\title{
The selective epidermal growth factor receptor tyrosine kinase inhibitor PD153035 suppresses expression of prometastasis phenotypes in malignant pleural mesothelioma cells in vitro
}

George W. Cole, Jr, MD, Annette M. Alleva, MD, Rishindra M. Reddy, MD, Justin B. Maxhimer, BA, JingTong Zuo, MD, David S. Schrump, MD, FACS, and Dao M. Nguyen, MD, FRCSC, FACS

Objective: Malignant pleural mesothelioma is notoriously refractory to aggressive multimodality therapy. Epidermal growth factor receptor expression has been observed on malignant pleural mesothelioma cells. Epidermal growth factor receptormediated signaling promotes tumorigenesis and metastasis of cancer cells. The purpose of this study is to evaluate the ability of the epidermal growth factor receptor tyrosine kinase inhibitor PD153035 to abrogate the expression of prometastasis phenotypes in malignant pleural mesothelioma cells in vitro.

Methods: Epidermal growth factor receptor expression of malignant pleural mesothelioma cells and primary normal cells was quantitated by means of flow cytometry. PD153035-mediated growth inhibition was determined by means of 1-(4,5-Dimethylthiazol-2-yl)-3,5-diphenylformazan and clonogenic assays. Cell motility and invasion of extracellular matrix was evaluated with in vitro woundhealing and Matrigel invasion assays, respectively. Vascular epidermal growth factor levels in conditioned media were measured by using enzyme-linked immunosorbent assay.

From the Section of Thoracic Oncology, Surgery Branch, Center for Cancer Research, National Cancer Institute, National Institutes of Health, Bethesda, Md.

Read at the Eighty-fourth Annual Meeting of The American Association for Thoracic Surgery, Toronto, Ontario, Canada, April 25-28, 2004.

Received for publication April 23, 2004; revisions received Oct 5, 2004; accepted for publication Oct 12, 2004

Address for reprints: Dao M. Nguyen, MD, Room 2B07, Building 10, 10 Center Dr, Bethesda, MD 20892 (E-mail: Dao_Nguyen@ nih.gov).

J Thorac Cardiovasc Surg 2005;129: $1010-17$

$0022-5223 / \$ 30.00$

Copyright $\odot 2005$ by The American Association for Thoracic Surgery

doi:10.1016/j.jtcvs.2004.10.040
Results: Epidermal growth factor receptor expression was detected on all 6 cultured malignant pleural mesothelioma cells, with 4 of 6 having normal receptor expression and 2 of 6 overexpressing the receptor. PD153035 suppressed cell motility and cell invasion through a Matrigel membrane, regardless of the baseline epidermal growth factor receptor expression. Decreased vascular epidermal growth factor production and significant inhibition of growth only occurred in malignant pleural mesothelioma cells that overexpress epidermal growth factor receptor.

Conclusions: Epidermal growth factor receptor tyrosine kinase inhibitor PD153035 significantly inhibited motility and invasion in malignant pleural mesothelioma cells in vitro, regardless of their epidermal growth factor receptor expression levels. Inhibition of epidermal growth factor receptor-dependent signaling might be a useful strategy to diminish malignant pleural mesothelioma recurrence after aggressive cytoreductive surgery.

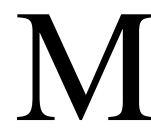
alignant pleural mesothelioma (MPM) is a rare but deadly disease characterized by unrelenting locoregional invasion and encasement of contiguous intrathoracic organs leading to death. Aggressive multimodality therapy involving radical extrapleural pneumonectomy coupled with postresection chemotherapy-radiotherapy, although effective in a small subset of patients with MPM, has substantial treatment-related complications. ${ }^{1}$ In conjunction with ongoing clinical efforts to design more effective treatments for MPM, considerable 
Cultured Cancer Cells

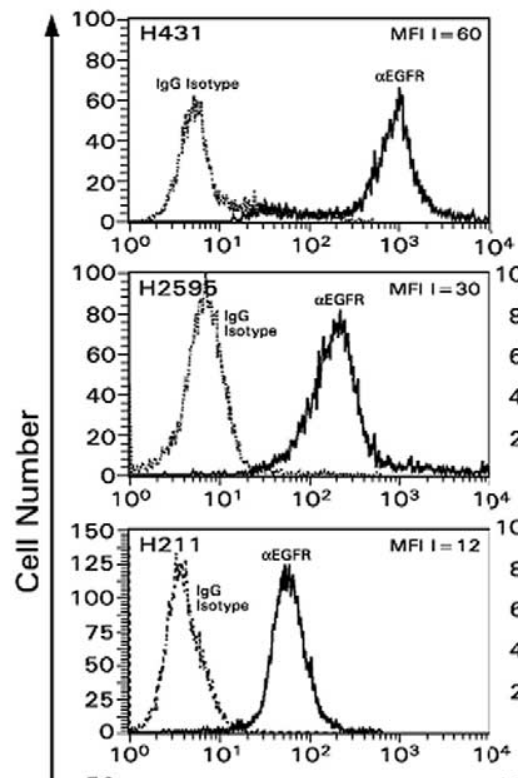

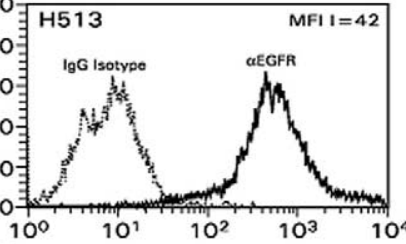
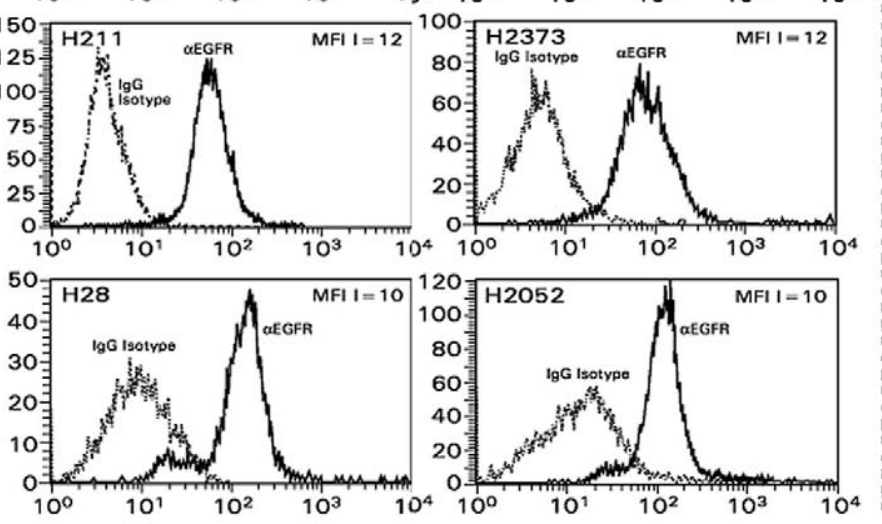

FITC Mean Fluorescence Intensity

Figure 1. Flow cytometric analysis of EGFR expression on a panel of 6 cultured MPM cells and 3 primary normal cells (normal skin fibroblast, normal human skin epithelial keratinocyte [NHEK], and normal human bronchial epithelial cells [NHBE] in vitro. The EGFR-overexpressing $\mathrm{H} 431$ cells serve as the positive control. The magnitude of EGFR expression is indicated by the EGFR-fluorescein isothiocyanate MFI index, as described in the "Materials and Methods" section. Representative data of 3 independent experiments with similar results are shown.

attention has been focused on the development of targeted molecular therapy for this disease.

The development of a malignant tumor from its microscopic focus, similar to the formation of metastasis, is a multistep process. This process involves the acquisition of multiple cellular phenotypes, such as proliferation, resistance to apoptosis, motility, and invasion through extracellular ground substance, as well as the ability to stimulate angiogenesis (collectively termed prometastasis phenotypes). Substantial experimental evidence has indicated the important role of members of the epidermal growth factor receptor (EGFR) superfamily (particularly ErbB1/EGFR or erbB2/HER2/neu) in promoting malignant transformation and metastasis. ${ }^{2}$ Furthermore, overexpression of EGFR or HER2/neu has been observed to correlate with locally advanced disease, distant metastasis, resistance to chemoradiation and diminished survival in patients with breast, lung, esophageal, and ovarian carcinomas. ${ }^{3,4}$ Stimulation of
Primary Normal Cells
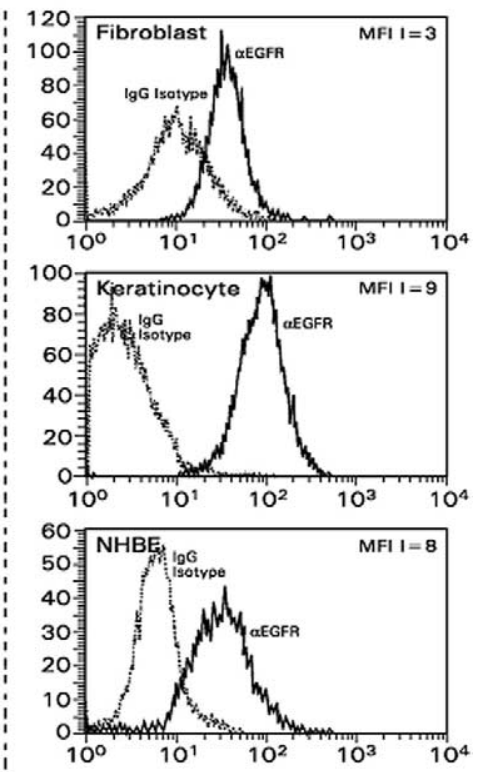

EGFR by its natural ligands, transforming growth factor $\alpha$ or epidermal growth factor, through either an autocrine or paracrine mechanism results in activation of its intrinsic tyrosine kinase activity and receptor autophosphorylation. Activated EGFR, through recruitment of multiple adaptor molecules (eg, SOS and Grb2), as well as functional proteins (eg, PI3K p110 subunit), initiates parallel cascades of downstream intracellular signaling pathways, namely the Ras/Raf/ MAPK (ERK1/2), Rac/Rho, PI3K/AKT, and STAT pathways. The biologic responses from such a diverse intracellular signaling include cell proliferation, survival, motility, invasion, adhesion, and angiogenesis. ${ }^{2}$

Selective inhibition of the EGFR tyrosine kinase activity with pharmacologic antagonists or blocking monoclonal antibodies in cancer cells expressing high levels of EGFR through abrogation of receptor-mediated transduction of signals to multiple intracellular pathways effectively suppresses tumor cell growth and enhances their sensitivity to 


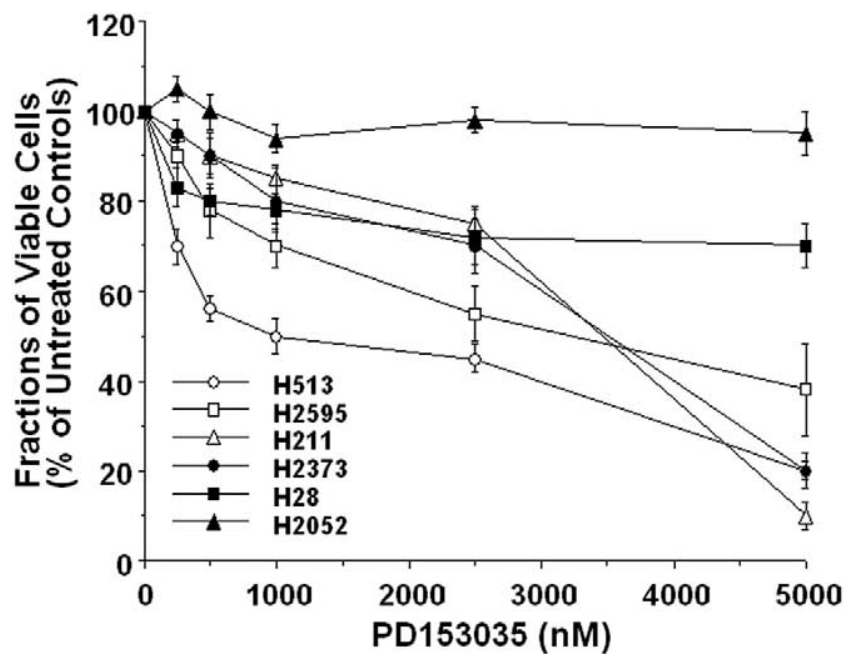

Figure 2. Growth-inhibitory effect of PD153035 on cultured MPM cells expressing different levels of EGFR. Cells seeded in 96-well microtiter plates were continuously treated with varying concentrations of PD153035 for $\mathbf{9 6}$ hours. Cell viability was determined by using the MTT assay and expressed as a percentage of untreated control cells. PD153035 IC I0 $_{50}$ values of each cell line derived from the respective dose-response curves are shown in Table 1. Data are expressed as means \pm SEM of 4 independent experiments.

cytotoxic therapy. ${ }^{5}$ Preclinical studies of EGFR antagonists that showed profound biologic effects of the anti-EGFR therapy have frequently been performed in cultured cancer cell lines expressing extremely high levels of EGFR, such as H431 or DiFi cells. ${ }^{6}$ However, little attention has been placed on the effect of EGFR antagonists on cancer cells with normal levels of EGFR. Additionally, there has been little investigation into EGFR antagonist influence on cellular phenotypes other than proliferation and survival, such as cell motility or cell invasion, which are equally important in promoting tumorigenesis.

The primary objective of this study is to evaluate the effect of the pharmacologic EGFR antagonist PD153035, a well-described EGFR-selective tyrosine kinase inhibitor (TKI) ${ }^{7}$ on expression of prometastasis phenotypes in cultured MPM cells that express different levels of EGFR. The other objective is to determine whether there is a correlation between the levels of baseline EGFR expression and the biologic response to EGFR TKI by using multiple cellular phenotypes as end points.

\section{Materials and Methods \\ Cells and Reagents}

Cultured MPM cells and EGFR-positive H431 cells were maintained in RPMI medium supplemented with $10 \%$ fetal calf serum (FCS), glutamine (1 mmol/L), and antibiotics (streptomycin, $100 \mathrm{mg} / \mathrm{mL}$; penicillin, $100 \mathrm{U} / \mathrm{mL}$ ). Normal human skin keratin-

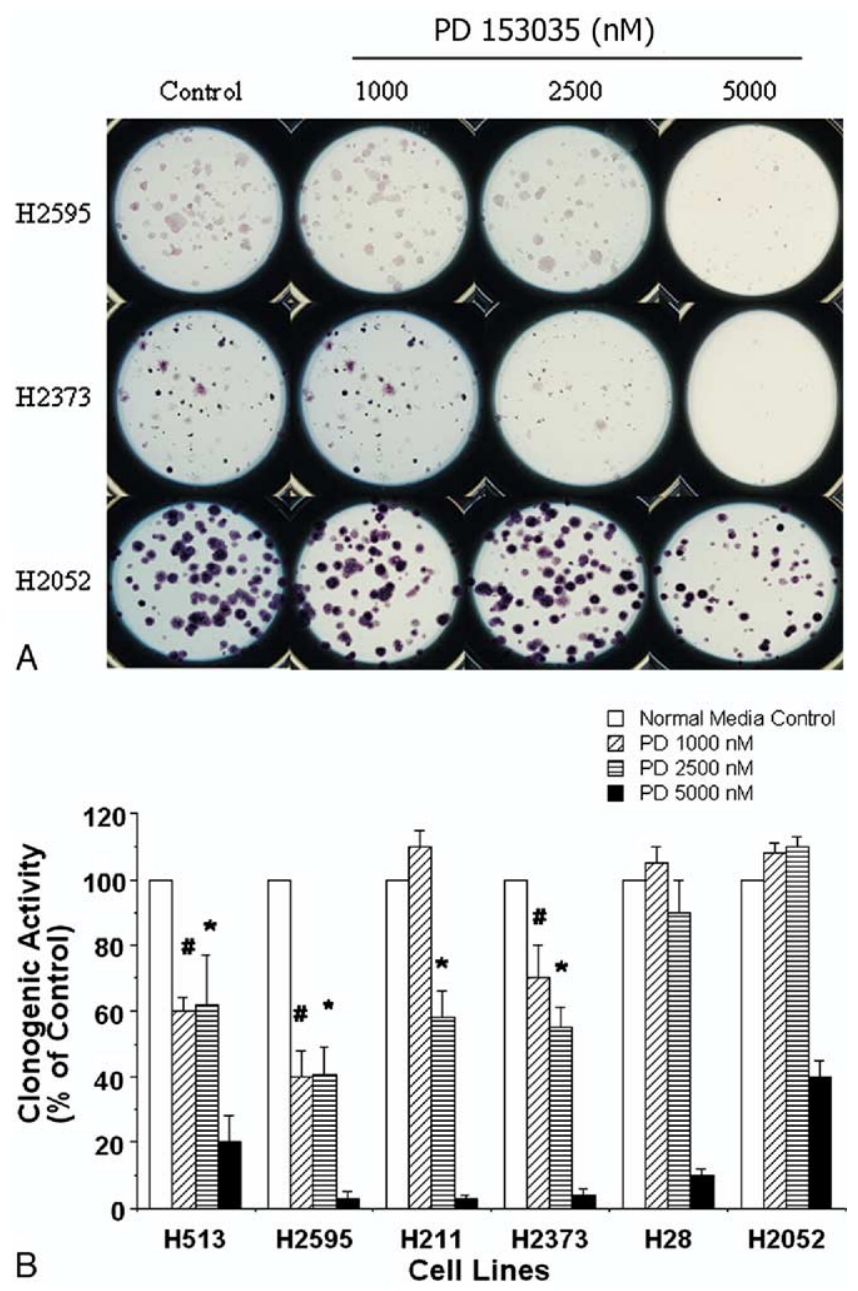

Figure 3. Inhibition of clonogenic activity of cultured MPM cells by PD153035 (PD). Cells were seeded in 6-well tissue culture plates and continuously treated with PD153035 for 10 days, whereas individual colonies were formed from individual seeded cells. The clonogenicity of control or PD153035-treated cells was recorded by means of digital photography $(A)$ as representative assays of H2595, H2373, and H2052 are shown here and quantitated by means of image analysis (B), as described in the "Materials and Methods" section. Data are expressed as means \pm SEM of 4 independent experiments $(\# P=.0003$ to $<.0001$ for 1000 nmol/L PD153035-treated vs control cells; ${ }^{*} P<.0001$ for 2500 nmol/L PD153035-treated vs control cells).

ocytes, dermal fibroblasts, and bronchial epithelial cells were purchased from Clonetics (Cambrex Int, Walkerville, Md) and cultured as per the instructions of the vendor. PD153035 was obtained from Tocris Cookson, Inc (Ellisville, Mo), dissolved in dimethyl sulfoxide as $10 \mathrm{mmol} / \mathrm{L}$ stocks, and stored at $-20^{\circ} \mathrm{C}$.

Flow Cytometric Analysis of EGFR Expression

The surface expression of EGFR on cultured MPM cells or primary normal cells was determined by means of indirect immuno- 


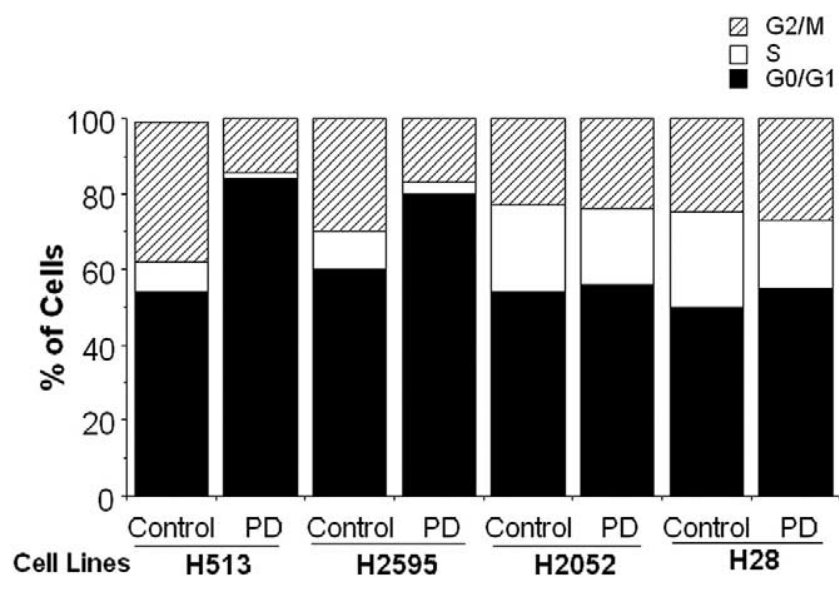

Figure 4. Cell-cycle analysis of representative MPM cells after 48 hours of exposure to PD153025 (PD; 2500 nmol/L), as determined by means of propidium iodide staining and flow cytometry. Representative data of 3 independent experiments with similar results are shown here.

fluorescence staining and flow cytometry, as described elsewhere. ${ }^{8}$ The density of EGFR expression on the cell surface was indicated by the EGFR mean fluorescence intensity (MFI) index (the ratio of the MFI of EGFR staining and the MFI of the IgG isotype control).

\section{Cell Proliferation and Clonogenic Assays}

Cultured MPM cells were seeded in 96-well plates (3000-5000 cells per well) and subsequently treated with PD153035 (250$5000 \mathrm{nmol} / \mathrm{L}$ ) for 96 hours, with a replacement of fresh media (with or without PD153035) at 48 hours. Cell viability of control and PD153035-treated cells was quantitated with 1-(4,5-dimethylthiazol-2-yl)-3,5-diphenylformazan (MTT; Sigma-Aldrich, St Louis, Mo). The PD153035 IC $_{50}$ values (con-

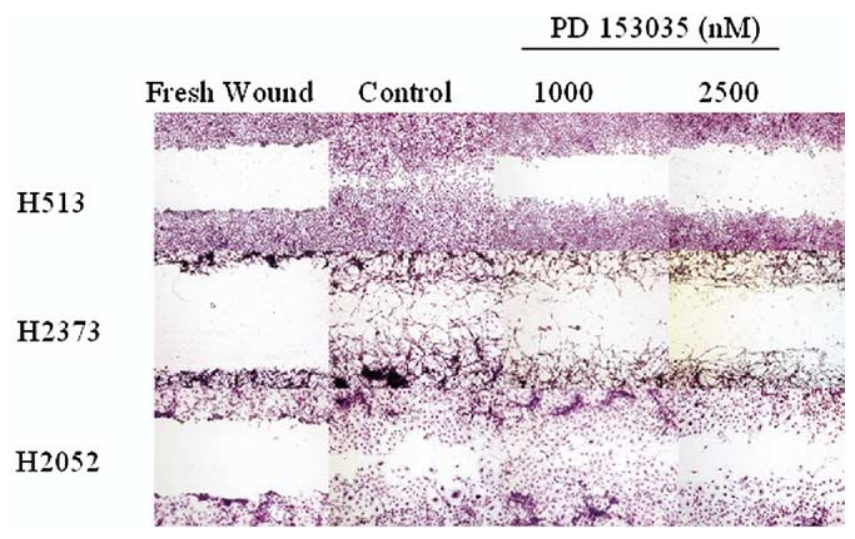

Figure 5. Inhibition of cell motility by PD153035 in cultured MPM cells, as evaluated by using the in vitro wound healing assay. Cell motility, as evidenced by narrowing of the wound edge, is shown. Fresh wound is shown as a baseline control of the assay. Representative digital photomicrographs are shown here.

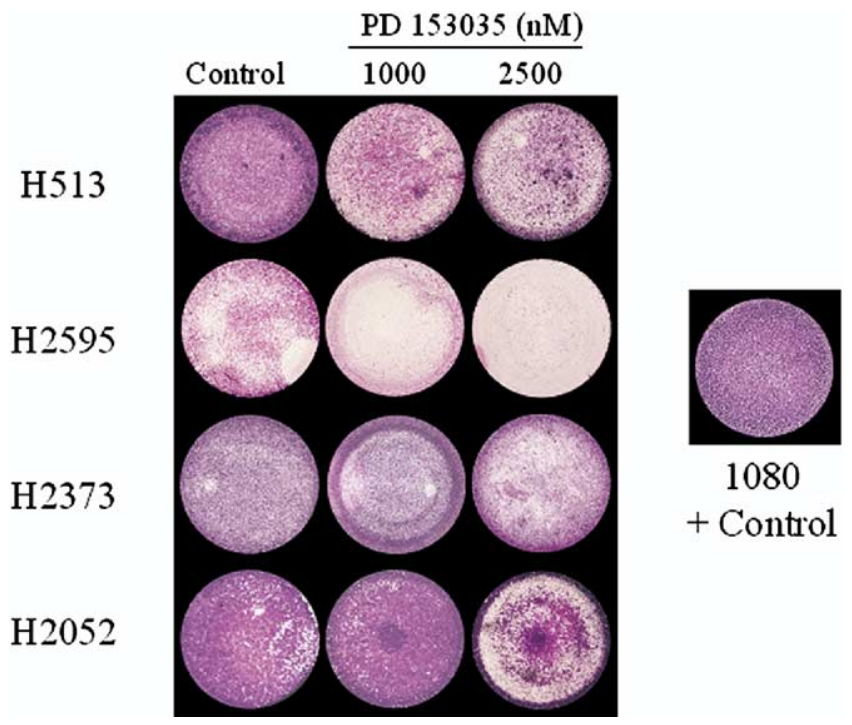

Figure 6. Inhibition of cell invasion-migration through the extracellular matrix Matrigel by PD153035 in cultured MPM cells. The magnitude of cell invasion through the Matrigel membrane was recorded by means of digital photomicrography. Representative pictures are shown here.

centrations of PD153035 that mediated 50\% inhibition of cell proliferation) were extrapolated from the respective dose-response curves. Cultured MPM cells were seeded at 300 to 1000 cells per well in 6-well plates and continuously exposed to PD153035 (1000, 2500, and $5000 \mathrm{nmol} / \mathrm{L})$ for 3 days. Cells were further cultured in fresh PD153035-free complete media for 7 more days. Cell colonies were then fixed with $1 \%$ paraformaldehyde and stained with Diff-Quick (Dade Behring Inc, Newark, Del). The colonies were photographed with a digital camera, and colony density was quantitated by means of image analysis with Adobe Photo-Shop 5.0 (Adobe Inc, San Jose, Calif).

\section{Cell Motility Assay}

Cell motility was evaluated by using the in vitro wound-healing assay, as previously described. ${ }^{9}$ MPM cells were seeded in 12-well plates to obtain $90 \%$ confluence. After an overnight incubation, wounds were made by scratching the cell monolayer with a sterile plastic pipette tip. Cells were then treated with PD153035 (1000, 2500 , or $5000 \mathrm{nmol} / \mathrm{L}$ ) for 24 hours. Movement of cells from wound edges into the wounds was indicative of cell motility. Cells were fixed with $1 \%$ paraformaldehyde, and the magnitude of wound healing was recorded with digital microphotography.

\section{Matrigel Invasion Assay}

Cell migration and invasion through the Matrigel membrane was quantitated by using the commercially available cell-invasion kit (Chemicon Int, Temecula, Calif). MPM cells treated with PD153035 (1000, 2500, or $5000 \mathrm{nmol} / \mathrm{L})$ in FCS-free media were seeded in the invasion chambers and stimulated to migrate and invade the Matrigel-containing filter by using serum-containing 
TABLE 1. Summary of the effect of the EGFR TKI PD153035 on cellular expression of prometastasis phenotypes (PD153035 $=2500 \mathrm{nmol} / \mathrm{L}$ )

\begin{tabular}{|c|c|c|c|c|c|c|}
\hline Cell lines & $\begin{array}{l}\text { EGFR MFI } \\
\text { index }\end{array}$ & $\begin{array}{c}\text { PD153035 } \\
\text { IC }_{50}(\mathrm{nmol} / \mathrm{L})\end{array}$ & $\begin{array}{c}\text { Reduction of } \\
\text { clonogenicity } \\
\text { (vs control) }\end{array}$ & $\begin{array}{l}\text { Inhibition of } \\
\text { motility }\end{array}$ & $\begin{array}{l}\text { Inhibition of } \\
\text { invasion }\end{array}$ & $\begin{array}{c}\text { Reduction of VEGF } \\
\text { production } \\
\text { (vs control) }\end{array}$ \\
\hline H513 & 42 & $1915 \pm 153$ & $40 \% *$ & +++++ & ++++ & $48 \% *$ \\
\hline $\mathrm{H} 2595$ & 30 & $2882 \pm 527$ & $60 \% *$ & +++++ & ++++++ & $40 \% \dagger$ \\
\hline H211 & 12 & $3119 \pm 193$ & $42 \% *$ & ++++ & +++ & $14 \%$ \\
\hline H2373 & 12 & $3517 \pm 189$ & $45 \% *$ & +++++ & +++++ & $10 \%$ \\
\hline $\mathrm{H} 28$ & 10 & $>5000$ & $10 \%$ & +++ & +++++ & $30 \% \ddagger$ \\
\hline H2O52 & 10 & $>5000$ & 0 & +++++ & ++++ & 125 \\
\hline
\end{tabular}

$E G F R$, Epidermal growth factor receptor; $T K I$, tyrosine kinase inhibitor; $I C_{50}$, inhibitory concentration of $50 \%$; VEGF, vascular epidermal growth factor. $* P$ $\leq .0001 . \dagger P=.0025 . \ddagger P=.025$.

media in the lower wells. Filters that contained cells that successfully traversed the Matrigel layer were stained with the cell stain provided in the kit and photographed with a digital camera.

\section{Vascular Epidermal Growth Factor Assay}

Levels of vascular epidermal growth factor (VEGF) in conditioned media of MPM cells (baseline control cells or after PD153035 treatment $[1000,2500$, or $5000 \mathrm{nmol} / \mathrm{L}]$ for 48 hours) were measured by means of enzyme-linked immunosorbent assay (R\&D Biosystems, Minneapolis, Minn). VEGF levels in the conditioned media were normalized for total cellular protein and expressed as picograms per milliliter per milligram of cellular protein. Deferoxamine $(100 \mu \mathrm{mol} / \mathrm{L})$ was used to simulate the hypoxic condition.

\section{Data Presentation and Statistical Analysis}

Data are presented as means \pm SEM of at least 4 independent experiments with similar results. The 2-tail Student $t$ test or analysis of variance with the Bonferroni post test for pairwise comparisons was used as indicated for statistical analysis (GraphPad software, San Diego, Calif).

\section{Results}

\section{EGFR Expression on Cultured MPM Cells}

All MPM cell lines expressed EGFR, as determined by means of immunofluorescence staining and flow cytometry. High levels of EGFR were detected on H513 and H2595 cells with MFI indexes of 43 and 30, respectively compared with an MFI index of 60 in H431-positive control cells. The other 4 cultured MPM cells had EGFR levels (MFI indexes ranging from 9 to 13) that were similar to those of primary normal cells of ectodermal and mesodermal origin (Figure 1).

\section{Growth-inhibitory Effect of PD153035 on MPM Cells}

Continuous exposure of MPM cells to PD153035 resulted in a significant dose-dependent inhibition of cell proliferation only in cell lines expressing high levels of EGFR (H513 and $\mathrm{H} 2595$ ), with PD153035 $\mathrm{IC}_{50}$ values ranging from 1800 to $2900 \mathrm{nmol} / \mathrm{L}$. Inhibition of cell proliferation was noticeable only at a high concentration of PD153035 at $5000 \mathrm{nmol} / \mathrm{L}$
(H211 and H2373) or absent (H28 and H2052) in cell lines with normal EGFR (Figure 2). The profound growthinhibitory effect of PD153035 in cells expressing high levels of EGFR was duplicated with the clonogenic assay (Figure 3). Substantial suppression of the clonogenicity was observed in 2 high-EGFR cell lines, H513 and H2595 (at PD153035 concentrations as low as $1000 \mathrm{nmol} / \mathrm{L}$ ), as well as in 2 cell lines expressing normal EGFR levels, H211 and $\mathrm{H} 2373$ (at PD153035 concentrations of $>2500 \mathrm{nmol} / \mathrm{L}$ ). Interestingly, PD153035 at $5000 \mathrm{nmol} / \mathrm{L}$ profoundly abrogated the clonogenic activity of the remaining 2 cultured MPM cell lines with normal EGFR expression levels (H28 and H2052) that were not at all growth inhibited by PD153035 when evaluated by using the MTT cell-proliferation assay. In cells that were growth inhibited by PD153035 (eg, H513 or H2595), but not in those that were refractory to PD153035 effect (H2595 or H28), there was a significant accumulation of cells in the G0/G1 phase of the cell cycle (with concomitant reduction of cells in the $\mathrm{S}$ and G2/M phases), which is indicative of arrest of cell-cycle progression at the G1/S checkpoint (Figure 4). There was no apoptosis of PD153035-treated cells (2500 or $5000 \mathrm{nmol} / \mathrm{L}$ for up to 5 days), as determined by means of TUNEL-based ApoBrdU assay (data not shown).

\section{Inhibition of Cell Motility and Invasion of Matrigel Membrane In Vitro by PD153035}

PD153035 treatment mediated significant suppression of cell motility of all cultured MPM cells in vitro, as evaluated by using the wound-healing assay (Figure 5). Similarly, PD153035 treatment also strongly inhibited cellular invasion-migration through the Matrigel membrane in response to the chemoattractant effect of FCS (Figure 6). The magnitudes of PD153035-mediated suppression of cell motility or cell invasion-migration through the Matrigel membrane versus control levels were semiquantitatively scored from $1+$ (minimal inhibition) to $5+(>90 \%$ inhibition) and summarized in Table 1. In contrast to its growth-inhibitory 
effect, which seemed to be positively correlated with EGFR expression status, there appeared to be little correlation between the levels of EGFR expression and the magnitudes of inhibition of cell motility and cell invasion through the in vitro extracellular matrix Matrigel.

\section{Inhibition of VEGF Production at Baseline and After Deferoxamine-simulated Hypoxic Condition by PD153035}

The levels of VEGF in conditioned media of cultured MPM cells under baseline and after simulated hypoxic condition with or without PD153035 exposure were measured by means of enzyme-linked immunosorbent assay and normalized for the total cellular protein of the cell pellets. High levels of VEGF were noted in the conditioned media of H513 and H2595 (high EGFR) and H28 (normal EGFR) cells compared with lower levels of VEGF in other cultured MPM cells (H211, H2373, and H2052 cells; Figure 7, A). PD153035 treatment significantly suppressed VEGF production by those cells with high baseline levels (30\%-50\% reduction from baseline control levels, $P=.025$ to .0001 ; Figure 7, A). On the other hand, PD153035 treatment did not alter VEGF production in cell lines expressing normal EGFR with lower baseline VEGF levels. Hypoxia is a powerful stimulus for upregulation of VEGF production in normal physiologic and pathologic conditions. Deferoxamine treatment was used to simulate the hypoxic condition in representative MPM cell lines (high-EGFR H513 cells and normal-EGFR H2052 and H211 cells). Chemically stimulated hypoxia caused 2.2-fold (H513 and H211) to 3 -fold (H2052) increases of VEGF levels in the conditioned media. PD153035 treatment during the hypoxic condition differentially suppressed hypoxia-induced VEGF upregulation only in high-EGFR H513 cells but not in normal-EGFR H2052 or H211 cells (Figure 7, B).

\section{Discussion}

EGFR-targeted therapy was conceived on the basis of the observation that dysregulated EGFR-mediated signal transduction plays an important role in carcinogenesis, tumor progression, and a significant proportion of cancers of different histology and expresses increased levels of EGFR when compared with normal cells. ${ }^{4}$ Moreover, it is believed that cancer cells expressing high EGFR levels depend on this receptor for proliferation-survival and thus are more susceptible to EGRF blockade. Differential expression of EGFR in tumor cells versus nontumor normal tissues can provide an exploitable therapeutic window in cancers known to overexpress EGFR. Preclinical studies of antiEGFR strategies showed promising and at times spectacular results of significant induction of apoptosis (in vitro and in vivo) and regression of established tumor xenografts. ${ }^{10}$ Further preclinical evaluation of the anticancer effect of selective EGFR TKI has shown mixed results. Some investiga-
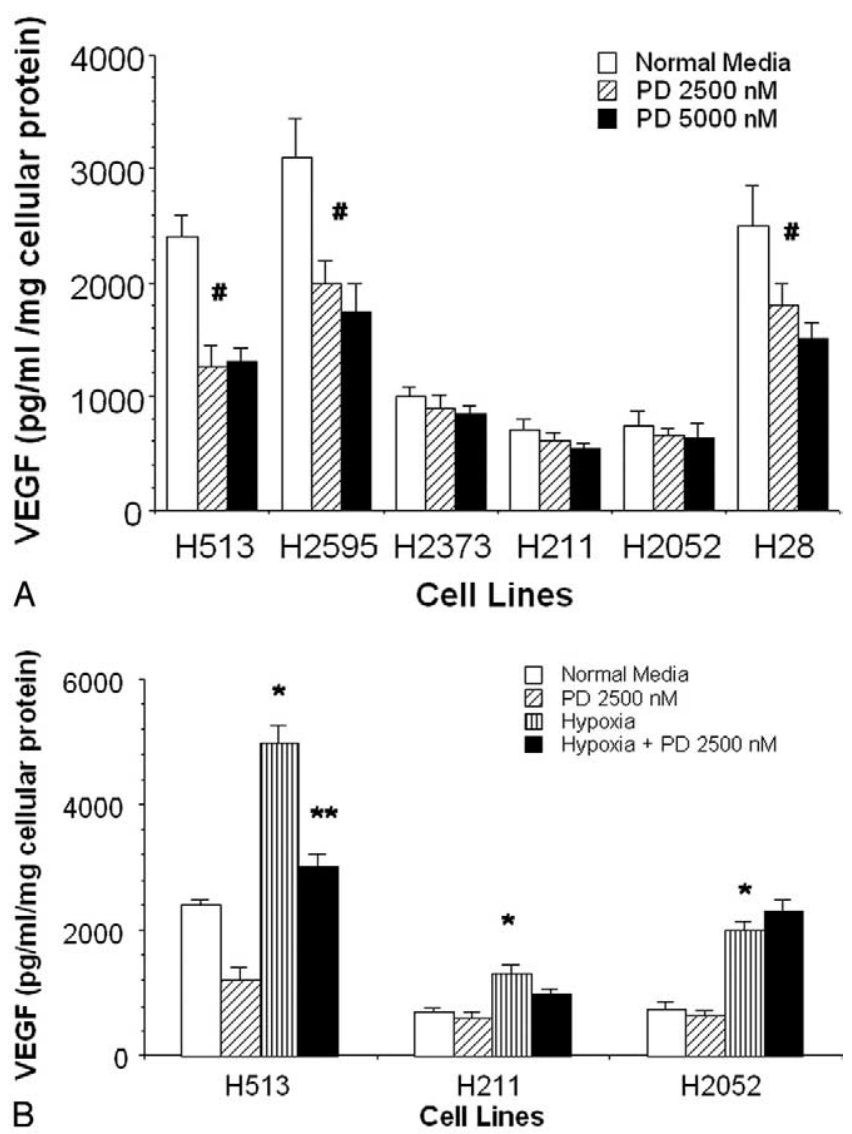

Figure 7. The effect of PD153035 (PD) on VEGF production and secretion into the conditioned media of cultured MPM cells at baseline (\#P=.0001 [H513], $P=.0025$ [H2595], and $P=.025$ [H28] for cells treated with $200 \mathrm{nmol} / \mathrm{L}$ PD153035 vs control cells; $A$ ) and under simulated hypoxic condition (deferoxamine) in representative H513, H2052, and $\mathrm{H} 211$ cells $\left(^{*} P=.0008\right.$ [H513], $P=.004$ [H211], and $P=.002$ [H2052], hypoxia vs control; ${ }^{*} P=.0008$, hypoxia vs PD153035/hypoxia; B). Data are expressed as means \pm SEM of 4 independent experiments.

tors reported correlation between the levels of EGFR expression $^{7}$ and response to EGFR blockade, whereas others showed no relationship between EGFR levels and EGFR TKI-mediated inhibition of cell proliferation. ${ }^{11}$ The in vitro cell proliferation assay is frequently performed when evaluating the growth-inhibitory property of drugs because it can be readily used in high throughput screenings. Our experiments, using the standard monolayer proliferation assay, indicated that cell lines expressing high levels of EGFR (H513 and H2595) were significantly growth inhibited, whereas other MPM cells with normal EGFR levels were much less sensitive or even refractory to the EGFR TKI PD153035. However, the clonogenic assay indicated that $5000 \mathrm{nmol} / \mathrm{L}$ PD153035 effectively suppressed forma- 
tion of visible colonies in all cell lines evaluated. Even though PD153035 is EGFR selective at nanomolar concentrations, it is unclear whether PD153035 at $5000 \mathrm{nmol} / \mathrm{L}$ would exert an inhibitory effect on other tyrosine kinases. Moreover, pharmacokinetic analysis indicated that the drug concentration achievable at the maximally tolerated dose of oral EGFR TKI ZD 1839 (Iressa; AstraZeneca, Wilmington, Del) was approximately $2000 \mathrm{nmol} / \mathrm{L}$. The in vitro biologic effects of higher concentrations of EGFR TKI, such as PD153035, as seen in our study or reported by other authors using ZD 1839, might be irrelevant. ${ }^{12}$

Cell proliferation is only one component of the molecularcellular cascade of tumor development and metastasis. Cell motility and invasion through extracellular matrix are other facets of malignant phenotypes. The current cellular paradigm of metastasis formation suggests that it is a multistep process: detachment from tumor mass, migration through the extracellular matrix, lymphatic-hematologic dissemination, exiting from the vasculature, formation of metastatic deposits, and recruitment of angiogenesis for macroscopic tumor development. The ability of cancer cells to migrate through the artificial extracellular matrix membrane Matrigel frequently correlates with their invasiveness in vivo. ${ }^{13}$ In contrast to its ability to inhibit cell proliferation only in cells expressing increased EGFR levels at a reasonable drug concentration, PD153035 treatment strongly suppresses cell motility and cell migrationinvasion through Matrigel membrane in vitro of all cultured MPM cells, regardless of their baseline EGFR expression at PD153035 concentrations of 1000 to $5000 \mathrm{nmol} / \mathrm{L}$. The short duration of the assay (24 hours) precludes the possibility that such inhibition of cell kinesis is related to the antiproliferation effect of PD153035 in susceptible cell lines (H513 and H2595). Even though we did not evaluate the effect of EGFR blockade on production of matrix metalloproteinases (MMPs) in this study, our previous works, ${ }^{8,14}$ as well as those of others ${ }^{15}$ have demonstrated significant inhibition of the secretion of MMP-9/MMP-2, as well as the reduction of MMP-2/ MMP-9, protease activity in the conditioned media of cultured cancer cells treated with anti-EGFR therapy.

EGFR-mediated signaling through the PI3K/AKT pathway, particularly in the hypoxic condition, has been shown to transcriptionally regulate $V E G F$ gene expression. ${ }^{16}$ It is interesting to see higher levels of baseline VEGF in conditioned media of $\mathrm{H} 2595$ and $\mathrm{H} 513$ cells than in those of MPM cells with normal EGFR levels, such as H2052, H2373, and H211 cells. Significant inhibition of baseline VEGF production was observed in 2 high-EGFR cells (H513 and H2595) and only in 1 of 4 normal-EGFR MPM cells (H28). It is clear from our study that EGFR antagonists, such as the TKI PD153035, have a limited role in suppressing VEGF production in cultured MPM cells, particularly in those not overexpressing this proto-oncoprotein. Further works are in progress to evaluate the effect of EGFR inhibition on downstream signaling pathways in cell lines expressing different levels of this receptor to demonstrate the potential relationship between distinct signal transduction pathways and prometastatic phenotypes. Early-phase clinical trials suggest that EGFR TKIs have demonstrable clinical activity against a wide variety of solid tumors, including cancers of the lung, esophagus, ovary, and head and neck. ${ }^{17,18}$ Unfortunately, 2 large phase III trials failed to show the beneficial effects of combining EGFR TKI with cytotoxic chemotherapeutic agents, in contrast to preclinical studies. ${ }^{4}$ Ongoing investigations are underway to elucidate the molecular basis of cellular resistance to this treatment strategy: the importance of EGFR-phosphorylated EGFR in tumors and the presence of constitutive activation of the AKT pathway among others. ${ }^{19,20}$ On the other hand, dramatic responses to EGFR antagonists have been observed in a small subset of patients with lung cancer, particularly female nonsmokers with adenocarcinoma (bronchoalveolar carcinoma). ${ }^{21-23}$ Genetic analysis has identified somatic mutations in the tyrosine kinase domain of the EGFR gene (such as the missense mutation Leu858 $\rightarrow$ Arg858 [L858R] or the 18-base pair inframe deletion [delL747-P753insS]). $E G F R$ mutants have been shown to exhibit enhanced tyrosine kinase activity in response to epidermal growth factor and increased sensitivity to EGFR TKIs. ${ }^{19-21}$ It is unlikely that the cultured MPM cells used in this study have such a mutation of the EGFR gene because they are not very sensitive to the growth-inhibitory effect of PD153035, and these unique somatic mutations have only been identified in primary non-small cell lung cancers but not in other cancers of different histology. ${ }^{19}$ It is hard to expect compounds such as EGFR TKIs, which exert mainly cytostatic and not cytocidal activity, to produce objective response in patients with heavy tumor burdens. It is, however, more reasonable to develop EGFR TKI therapy as chemoprevention or as a long-term adjuvant after ablative therapy that reduces tumor burden to a microscopic state. It is in this state that EGFRtargeted therapy might have the best chance to be beneficial.

We thank Mr Arnold Mixon and Mr Shawn Farid (Flow Cytometry Core Facility, Surgery Branch, NCI/NIH) for their expert assistance and Mr Don White for statistical analysis.

\section{References}

1. Zellos L, Sugarbaker DJ. Current surgical management of malignant pleural mesothelioma. Curr Oncol Rep. 2002;4:354-60.

2. Nguyen DM, Schrump DS. Growth factor receptors as targets for lung cancer therapy. Semin Thorac Cardiovasc Surg. 2004;16:3-12.

3. Laskin JJ, Sandler AB. Epidermal growth factor receptor: a promising target in solid tumours. Cancer Treat Rev. 2004;30:1-17.

4. Hirsch FR, Varella-Garcia M, Bunn PA, Jr, et al. Epidermal growth factor receptor in non-small-cell lung carcinomas: correlation between gene copy number and protein expression and impact on prognosis. J Clin Oncol. 2003;21:3798-807.

5. Bruns CJ, Harbison MT, Davis DW, et al. Epidermal growth factor receptor blockade with $\mathrm{C} 225$ plus gemcitabine results in regression of 
human pancreatic carcinoma growing orthotopically in nude mice by antiangiogenic mechanisms. Clin Cancer Res. 2000;6:1936-48.

6. Petit AMV, Rak J, Hung M-C, et al. Neutralizing antibodies against epidermal growth factor and ErbB-2/neu receptor tyrosine kinases down regulate vascular endothelial growth factor production by tumor cells in vitro and in vivo angiogenic implications for signal transduction therapy of solid tumors. Am J Pathol. 1997;151:1523-30.

7. Bos M, Mendelsohn J, Young MK, et al. PD 153035, a tyrosine kinase inhibitor, prevents epidermal growth factor receptor activation and inhibits growth of cancer cells in a receptor number dependent manner. Clin Cancer Res. 1997;3:2099-106.

8. Nguyen DM, Desai S, Chen A, et al. Modulation of metastasis Phenotypes of non small cell lung cancer cells by 17-allylamino 17demethoxy geldanamycin. Ann Thorac Surg. 2000;70:1853-60.

9. Shaw RJ, Paez JG, Curto M, et al. The nf2 tumor suppressor, merlin, functions in Rac-dependent signaling. Dev Cell. 2001;1:63-72.

10. Kedar D, Baker CH, Killion JJ, et al. Blockade of the epidermal growth factor receptor signaling inhibits angiogenesis leading to regression of human renal cell carcinoma growing orthotopically in nude mice. Clin Cancer Res. 2002;8:3592-600.

11. Suzuki T, Nakagawa T, Endo H, et al. The sensitivity of lung cancer cell lines to the egfr-selective tyrosine kinase inhibitor zd1839 (iressa) is not related to the expression of egfr of her- 2 or to k-ras gene status. Lung Cancer. 2003;42:35-41.

12. Janne PA, Taffaro ML, Salgia R, Johnson BE. Inhibition of epidermal growth factor receptor signaling in malignant pleural mesothelioma. Cancer Res. 2002;62:5242-7.

13. Luo J, Lubaroff DM, Hendrix MJ. Suppression of prostate cancer invasive potential and matrix metalloproteinase activity by E-cadherin transfection. Cancer Res. 1999;59:3552-6.

14. Nguyen DA, Chen A, Desai S, et al. Down-regulation of malignant phenotypes in esophageal cancer cells expressing high levels of epidermal growth factor receptor (egfr) by the egfr-specific tyrosine kinase inhibitor PD153035. Proc Am Assoc Cancer Res. 2001; 42:854-55.

15. O-charoenrat P, Evans PR, Modjtahedi H, et al. Overexpression of epidermal growth factor receptor in human head and neck squamous carcinoma cell lines correlates with matrix metalloproteinase-9 expression and in vitro invasion. Int J Cancer. 2000;86:307-17.

16. Zhong H, Chiles K, Feldser D, et al. Modulation of hypoxia-inducible factor $1 \alpha$ expression by the epidermal growth factor/phosphatidylinositol 3-kinase /PTEN/AKT/FRAP pathway in human prostate cancer cells: implications for tumor angiogenesis and therapeutics. Cancer Res. 2000;60:1541-5.

17. Herbst RS, Giaccone G, Schiller JH. Natale RB. Miller V. Manegold $\mathrm{C}$, et al. Gefitinib in combination with paclitaxel and carboplatin in advanced non-small-cell lung cancer: a phase III trial-INTACT 2. J Clin Oncol. 2004;22:785-94.
18. Giaccone G, Herbst RS, Manegold C. Scagliotti G. Rosell R. Miller V, et al. Gefitinib in combination with gemcitabine and cisplatin in advanced non-small-cell lung cancer: a phase III trial-INTACT 1. $J$ Clin Oncol. 2004;22:777-84.

19. Navolanic PM, Steelman LS, McCubrey JA. EGFR family signaling and its association with breast cancer development and resistance to chemotherapy. Int J Oncol. 2003;22:237-52.

20. Janmaat ML, Kruyt FAE, Rodriguez JA, Giaccone G. Response to epidermal growth factor receptor inhibitors in non small cell lung cancer cells: limited antiproliferative effects and absence of apoptosis associated with persistent activity of extracellular signal-regulated kinase or Akt kinase pathways. Clin Cancer Res. 2003;9:2316-26.

21. Lynch TJ, Bell DW, Sordella R, Gurubhagavatula S. Okimoto RA, Brannigan BW, et al. Activating mutations in the epidermal growth factor receptor underlying responsiveness of non-small-cell lung cancer to gefitinib. N Engl J Med. 2004;350:2129-39.

22. Paez JG, Janne PA, Lee JC, Tracy S. Greulich H, Gabriel S, et al. EGFR mutations in lung cancer: correlation with clinical response to gefitinib therapy. Science. 2004;304:1497-500.

23. Pao W, Miller V, Zakowski M, Doherty J. Politi K, Sarkaria I, et al. EGF receptor gene mutations are common in lung cancers from "never smokers" and are associated with sensitivity of tumors to gefitinib and erlotinib. Proc Natl Acad Sci U S A. 2004;101:13306-11.

\section{Discussion}

Dr David R. Jones (Charlottesville, $\mathrm{Va}$ ). I enjoyed your talk very much. I have one quick question for you. Did you look at any specific proteins that might be affecting motility? In other words, why is there decreased motility, and what pathways do you think might be involved?

Dr Cole. That is a very good question. We are starting to look at those specific proteins right now. In fact, on the basis of data that we did not present here but that were just recently concluded, I have a sneaking suspicion that motility is going to be affected through AKT. We have used a specific AKT blocker in our same wound-healing assay, and the results of using that blocker are very dramatic.

Dr Yolonda Colson (Boston, Mass). Have you considered using the EGFR antibodies in this assay as well?

Dr Cole. I think that is something that we would like to explore. In terms of a clinical model, the EGFR antibodies, as you know, have to be delivered intravenously, and we were thinking of something more easily deliverable to the patient in terms of an oral medication, which led us to the TKIs. 